\title{
THE RESULTS OF SURGICAL REVASCULARIZATION IN PATIENTS WITH MULTI-VESSEL CORONARY DISEASE
}

Republican Research Center For Emergency Medicine, Tashkent, Uzbekistan

\begin{abstract}
Multi-vessel coronary artery disease constitutes 30 to $60 \%$ of morbidity of coronary heart disease (CHD). Surgical revascularization in patients with multi-vessel coronary artery disease is still a challenge. To evaluate the immediate results of hospital period: 30-day hospital mortality, postoperative complications and outcomes at 1 year follow-up the retrospective study was performed. We analyzed 90 patients with history of coronary artery disease who underwent coronary artery bypass grafting (CABG) surgery in 2014 by using the method of continuous sampling on the basis of a computer database of cardiac surgery department.

It was established, that surgical revascularization in patients with multi-vessel coronary disease can bring complete revascularization, eliminate signs of stenocardia, improve the quality of life and exercise tolerance in most patients in the 30-day period, and in 1 year after surgery.
\end{abstract}

KeyWords: coronary artery disease, coronary artery bypass grafting, postoperative complications and outcomes

\section{INTRODUCTION}

Multi-vessel coronary artery disease, which is characterized by the disease of two or more coronary arteries, has recently become increasingly common, and according to various reports constitutes 30 to $60 \%$ of morbidity of coronary heart disease (CHD). Surgical revascularization in patients with multi-vessel coronary artery disease is still a challenge. Although coronary artery bypass grafting (CABG) is the standard surgical revascularization in multi-vessel disease, improved techniques of interventional cardiology and the use of drug-eluting stents helped to increase them in patients with multi-vessel coronary artery disorders. According to several randomized trials percutaneous interventional $(\mathrm{PCl})$ procedures are accompanied by a lower incidence of postoperative and neurological complications. However, the frequency of revascularization after stenting is significantly higher than after CABG during the first year after the intervention.

\section{Corresponding Author:}

Abdusalom Abdurakhmanov, MD, PhD, Republican Research Center For Emergency Medicine, Tashkent, Uzbekistan. Email: ab.abdurakhmanov@yandex.com
The one of the largest multicenter randomized trial ARTS trial (Arterial Revascularization Therapy Study), which included 1205 patients, showed that the angina recurrence and the need for repeated revascularization one year after the $\mathrm{PCl}$ were observed more frequently than in patients after CABG: the need for repeated revascularization was 3.1\% among diabetic patients after surgery, and $22.3 \%$ after stenting $(\mathrm{p}<0.001)$. In our study we have analyzed the results of direct CABG, including early postoperative complications and mortality, as well as outcomes within 30 days and one year.

\section{PURPOSES, SUBJECTS and METHODS:}

\subsection{Purpose}

To evaluate the immediate results of hospital period: 30-day hospital mortality, postoperative complications and outcomes at 1 year follow-up after surgical revascularization in patients with multi-vessel coronary disease.

\subsection{Subjects \& Methods}

Our retrospective study involved 90 patients with history of 
2014 at the Republican Research Center for Emergency Medicine. We used the method of continuous sampling on the basis of a computer database of cardiac surgery department.

\section{Conflict of interests}

There is no conflict of interests.

\section{RESULTS AND DISCUSSION}

Data on demographic and clinical characteristics are shown in Table 1.

Table 1

Demographic and clinical characteristics of patients

\begin{tabular}{|l|c|}
\hline \multicolumn{1}{|c|}{ Baseline characteristics } & Abs.value (\%) \\
\hline Age & $56.04 \pm 0.9$ \\
\hline Gender: & $69(76.7 \%)$ \\
\hline$\bullet \quad$ Male & $21(23.3 \%)$ \\
\hline $\begin{array}{l}\text { The duration of the disease for over one } \\
\text { year }\end{array}$ & $75(83.3 \%)$ \\
\hline Duration of disease less than one year & $15(26.7 \%)$ \\
\hline Diabetes & $61(67.8 \%)$ \\
\hline Unstable stenocardia & $85(94.4 \%)$ \\
\hline Acute myocardial infarction & $5(5.6 \%)$ \\
\hline
\end{tabular}

The average age of the patients was $56.04 \pm 0.9$ years, among them $23.3 \%$ of women and $76.7 \%$ of men. The duration of the disease less than 1 year was observed in $26.7 \%$ of patients and $83.3 \%$ of patients had disease duration greater than one year. Diabetes mellitus was diagnosed in $67.8 \%$ of patients. The majority of patients were diagnosed with unstable stenocardia (94.4\%); and $5.6 \%$ of patients underwent surgery under emergency indications secondary to acute myocardial infarction.

Surgical access in all the cases was provided by a median sternotomy. Shunting index was 3.1. In 8 (8.9\%) cases we used heart-lung machine; the remaining 82 (91.1 $\%)$ of patients were operated off-pump (OPCAB). In 39 $(43.3 \%)$ cases, the left internal thoracic artery was used for grafting of the left anterior descending artery, and in one patient, the left and right internal thoracic artery were used. Types of interventions are presented in Table 2.

\section{Types of surgical intervention}

\begin{tabular}{|l|c|}
\hline \multicolumn{1}{|c|}{ Characteristics } & Abs.value (\%) \\
\hline Bypass grafting of 2 vessels & $17(18.9 \%)$ \\
\hline Bypass grafting of 3 vessels & $46(51.1 \%)$ \\
\hline Bypass grafting of 4 vessels & $26(28.9 \%)$ \\
\hline Bypass grafting of 5 vessels & $1(1.1 \%)$ \\
\hline Operation via cardiopulmonary bypass & $8(8.9 \%)$ \\
\hline Operation via OPCAB technology & $82(91.1 \%)$ \\
\hline
\end{tabular}

We evaluated the immediate results of hospital period: 30-day hospital mortality, postoperative complications and outcomes at 1 year follow-up.

Hospital mortality was $3.3 \%$ (3/90). The cause of mortality in all three cases was acute heart failure -3 , due to the initial severity of the disease, all patients underwent surgery with cardiopulmonary bypass.

Postoperative complications were observed in $9(10 \%)$ patients. The types of complications are presented in Table 3.

Table 3

The types of post-operative complications

\begin{tabular}{|l|c|}
\hline \multicolumn{1}{|c|}{ Complications } & Abs. value (\%) \\
\hline Heart failure & $2(2.2 \%)$ \\
\hline Neurological complications (stroke) & $1(1.1 \%)$ \\
\hline Postoperative bleeding & $2(2.2 \%)$ \\
\hline Wound complications: & $4(4.4 \%)$ \\
\hline$\bullet \quad$ Sternal dehiscense & $1(1.1 \%)$ \\
\hline$\bullet \quad$ Superficial wound infection & $2(2.2 \%)$ \\
\hline$\bullet \quad$ Purulent mediastinitis & $1(1.1 \%)$ \\
\hline
\end{tabular}

Among non-fatal complications, prevailing complications associated with post-operative wound infection were observed in $4(4.4 \%)$ patients. Postoperative bleeding in the early postoperative period was diagnosed in $2(2.2 \%)$ patients, and only in 1 case resternotomy was necessary to identify the source and achieve hemostasis.

Cardiac complications (heart failure requiring long-term inotropes) were observed in $2(2.2 \%)$ cases. In 
one case $(1.1 \%)$ with postmedical history of acute stroke, an operation using heart-lung machine resulted in deterioration of clinical signs. The duration of stay in the ICU after surgery was $2.4 \pm 0.5$. The duration of postoperative period in the clinic was $7.8 \pm 0.9$ days.

During one year follow up there were no cases of angina recurrence. The majority of patients $(95.6 \%)$ were considered as the first functional class according to Canadian stenocardia classification, the rest (4.4\%) were assessed as the second functional class. The patients who underwent surgery were found to have improved exercise tolerance, all patients after surgery were considered the second class of NYHA functional classification and within a year after surgery $83.3 \%$ have improved their physical tolerance.

\section{CONCLUSIONS}

Surgical revascularization in patients with multi-vessel coronary disease can bring complete revascularization, eliminate signs of stenocardia, improve the quality of life and exercise tolerance in most patients in the 30-day period, and in 1 year after surgery.

\section{REFERENCES}

1 Abu-Omar Y., Taggart DP. (2009). The present status of off-pump coronary artery bypass grafting. Eur $\mathrm{J}$ Cardiothorac Sur, 36: 312-21.

2 Boudriot $\mathrm{E}$, Thiele $\mathrm{H}$, Walther T, Liebetrau C, Boeckstegers P, Pohl $\mathrm{T}$ et al. (2011). Randomized comparison of percutaneous coronary intervention with sirolimus-eluting stents versus coronary artery bypass grafting in unprotected left main stem stenosis. J Am CollCardiol, 57:538-45.

3 Hillis LD, Smith PK, Anderson JL, Bittl JA, Bridges CR, Byrne JG et al. (2011). 2011 ACCF/AHA Guideline for Coronary Artery Bypass Graft Surgery: a report of the American College of Cardiology Foundation/American Heart Association Task Force on Practice Guidelines. Circulation, 124: e652-735.

4 Kim W.S., Lee J., Lee Y.T., Sung K., Yang J.H., Jun T.G. et al. (2008). Total arterial revascularization in triple- vessel disease with off-pump and aortic no-touch technique. Ann ThoracSurg, 86:1861-5.

5 Lev-Ran O., Loberman D., Matsa M., Pevni D., Nesher N., Mohr R. et al. (2004). Reduced strokes in the elderly: the benefits of untouched aorta off-pump coronary surgery. Ann ThoracSurg, 77:102-7.

6 Park S.J., Kim Y.H., Park D.W., Yun S.C., Ahn J.M., Song H.G. et al. (2011). Randomized trial of stents versus bypass surgery for left main coronary artery disease. $\mathrm{N}$ Engl J Med, 364:1718-27.

7 Puskas J.D., Kilgo P.D., Lattouf O.M., Thourani V.H., Cooper W.A., Vassiliades T.A. et al. (2008). Off-pump coronary bypass provides reduced mortality and morbidity and equivalent 10-year survival. Ann ThoracSurg, 86:113946.

8 Vallely M.P., Potger K., McMillan D., Hemli J.M., Brady P.W., Brereton R.J. et al. (2008). Anaortic techniques reduce neurological morbidity after off-pump coronary artery bypass surgery. Heart Lung Circ;17:299-304.

Received: $\quad$ 10-Nov. - 2016

Accepted: 20-Dec. - 2016 